\title{
Parathyroid carcinoma presenting with type 1 renal tubular acidosis
}

\author{
Priyankara SAS ${ }^{1}$, Arulmoly K${ }^{1}$, Jayasinghe VP ${ }^{1}$,Thambawita $\mathrm{HR}^{2}$, Ahilan $\mathrm{S}^{3}$, Majitha SI ${ }^{4}$ \\ ${ }^{1}$ Medical unit, Teaching Hospital Batticaloa \\ 2 Surgical unit, Teaching Hospital Batticaloa \\ ${ }^{3}$ Department of Pathology, Teaching Hospital Batticaloa \\ ${ }^{4}$ Department of Chemical pathology, Teaching Hospital Batticaloa
}

\begin{abstract}
Primary hyperparathyroidism usually caused by parathyroid adenoma, parathyroid hyperplasia or rarely parathyroid carcinoma (PTC). PTC accounts for $0.4 \%$ to $5.2 \%$ of all reported cases of hyperparathyroidism, which is approximately $0.2 \%$ to $0.5 \%$ of malignant endocrine tumors overall. Renal tubular acidosis has been reported to be associated with primary hyperparathyroidism. We report a case of parathyroid carcinoma diagnosed with only using the minor criteria who had concurrent renal tubular acidosis. This case highlights the importance of keeping the suspicion of PTC in mind when clinically hypercalcemic patients presented with abnormally high serum calcium levels.
\end{abstract}

Key words: Hypercalcemia, primary hyperparathyroidism, parathyroid carcinoma, type 1 renal tubular acidosis.

\section{Case presentation}

Sixty-one year old previously unevaluated male patient from Samanthurai presented with lethargy, constipation, vomiting and loss of weight for 6 months. He became wheel chair bound for last two weeks. There was no history of cold intolerance, fever, cough or altered bowel habits. He was neither a smoker nor an alcoholic. He was dehydrated and pale and did not have a neck lump. Rest of the examination was normal.

His serum ionized calcium was $3.68 \mathrm{mmol} / 1$, 24hour urinary calcium level 204mg. Microcytic hypochromic anemia in blood picture favored anemia in chronic disorder. Metabolic acidosis, high urinary $\mathrm{pH}(>5.3)$ favored diagnosis of type 1 renal tubular acidosis (blood PH 7.302, HCO38.8 mmol/1, urinary PH 7.36 with normal anion gap). Subsequent work up included an ultrasound scan of the neck that showed possible left lower parathyroid adenoma and sestemibi scan demonstrated increased up take of left lower parathyroid gland. He had normal study of contrast enhanced computer tomogram of brain, chest and abdomen and upper and lower gastrointestinal endoscopy examination. He underwent left hemi thyroidectomy. Specimen showed $1 \mathrm{~cm}^{3}$ mass on left lower pole of thyroid gland. Histology revealed parathyroid carcinoma with readily identifiable mitotic figure, vascular and capsular invasion in the Hematoxylin and Eosine (figure 1,2,3). Postoperative fasting calcium level was reduced to $8.5 \mathrm{mg} / \mathrm{dl}$.

Received: $17^{\text {th }}$ July 2018

Correspondence email: sumudupriyankara199@yahoo.com

https://orcid.org/0000-0002-6115-0251

This is an open-access article distributed under the terms of the Creative Commons Attribution License, which permits unrestricted use, distribution, and reproduction in any medium, provided the original author and source are credited (CC BY 4.0) 


\section{Table 1. Laboratory investigation results of the patient}

\begin{tabular}{lll} 
Test & Results & Normal Range \\
\hline White cell count & 6.9 & $4-11 \times 10^{9}$ \\
Hemoglobin & 7.6 & $11-14 \mathrm{~g} / \mathrm{dl}$ \\
Platlet count & 237000 & $150-450,000$ \\
Serum Na & 140 & $133-145 \mathrm{meq} / 1$ \\
Serum K & 2.7 & $3.4-5 \mathrm{meq} / 1$ \\
Calcium & 14.8 & $8.3-10.5 \mathrm{mg} / \mathrm{dl}$ \\
Phosphate & 1.6 & $2.5-4.9 \mathrm{mg} / \mathrm{dl}$ \\
TSH & 1.18 & $0.4-4.0 \mathrm{uIU} / \mathrm{ml}$ \\
Serum PTH & 46.32 & $1.5-7.2 \mathrm{pmol} / 1$ \\
Fasting blood sugar & 5.5 & $3.8-5.6 \mathrm{mmol}$ \\
S.Creatinine & 0.7 & $0.7-1.3 \mathrm{mg} / \mathrm{dl}$ \\
\hline
\end{tabular}

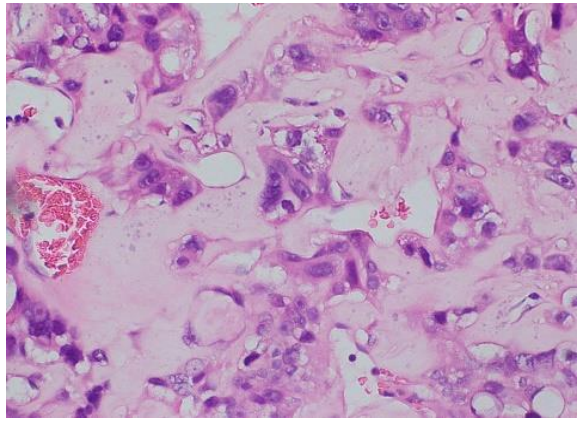

Figure 1: Parathyroid carcinoma showing vascular invasion

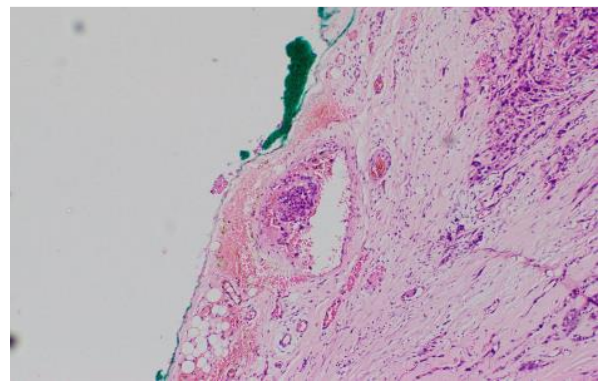

Figure 3: Parathyroid carcinoma showing mitotic figures

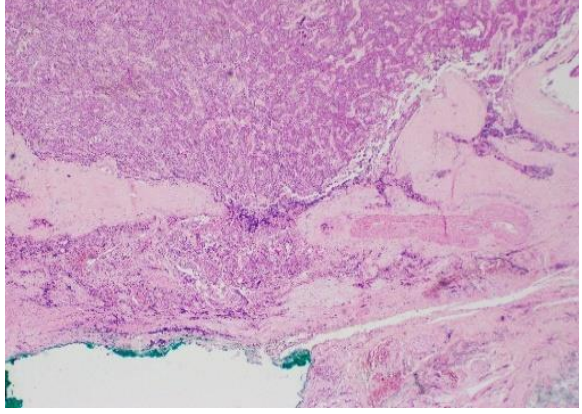

Figure 2: Parathyroid carcinoma showing capsular invasion 


\section{Discussion}

Primary hyperparathyroidism usually caused by parathyroid adenoma, parathyroid hyperplasia or rarely parathyroid carcinoma (PTC) (1). PTC accounts for $0.4 \%$ to $5.2 \%$ of all reported cases of hyperparathyroidism, which is approximately $0.2 \%$ to $0.5 \%$ of malignant endocrine tumors overall (2). The suspicion of malignancy should be in the setting of high calcium level more than $14 \mathrm{mg} / \mathrm{dl}$ and high parathyroid hormone (PTH) level ( $>$ five times of upper normal). Diagnosis PTC was difficult due to no single histopathological feature is pathognomonic for PTC $(3,4)$. There are absolute criteria (table 2) and features associated with malignancy. In the absence of the absolute criteria, at least two, preferably three or more features associated with malignancy should be there (5). The diagnosis was made upon the three minor criteria; mitotic figures, vascular and capsular invasion.

Hypokalemia, metabolic acidosis, high urinary $\mathrm{pH}(>5.3)$ favored diagnosis of type 1 renal tubular acidosis (6). Renal tubular acidosis has been reported to be associated with primary hyperparathyroidism. Renal tubular dysfunction due to significant hypercalciuria appears to be one of the proposed mechanisms. We came to final diagnosis as parathyroid carcinoma associated with type 1 renal tubular acidosis and hypercalcemia. Normal parathyroid function was ensured indirectly with repeated serum calcium levels after the surgery where we did not have facilities for serum PTH level measurements in frequently.

\section{Conclusion}

This case report highlights the importance of considering parathyroid carcinoma in patients with severe symptomatic hypercalcemia even in the absence of tell tailed features of parathyroid malignancy. In our case all imaging studies favored to parathyroid adenoma. In severe hypercalcemia, histology confirmation should be considered.

\section{Table 2. Absolute criteria and features associated with malignancy}

\section{Absolute criteria}

Features associated with malignancy.
1. Invasion into surrounding tissue (Thyroid. Esophagus, nerve, soft tissues)

2. Histological feature presented with distant metastasis
1. Capsular invasion

2. Vascular invasion

3. Readily identifiable mitotic figure $(>5 / 10 \mathrm{HPF})$

4. Broad intraturmoral fibrosis band splitting the parenchyma and separating expansile nodules

5. Coagulative tumor necrosis

6. Diffuse sheet- like monotonous small cells with high nuclear/cytoplasmic ratio

7. Diffuse cellular atypia

8. Macronucleoli present in many tumor cell 
1. Wei CH, Harari A. Parathyroid carcinoma: update and guidelines for management. Current Treatments Options in Oncology 2012; 13:11.

2. J Gawrychowski, G Kowalski, A Gawrychowska: Parathyroid cancer: Occurrence, diagnosis, treatment. Polski Przeglad Chirurgiczny 80: 506- 515,2008

3. Schantz A, Castleman B. Parathyroid carcinoma. A study of 70 cases. Cancer 1973; 31:600.

4. Bondeson L, Sandelin K, Grimelius L. Histopathological variables and DNA cytometry in parathyroid carcinoma. American Journal of Surgical Pathology 1993; 17:820.

5. Christoper D M fletcher diagnostic histopathology of tumor $2^{\text {nd }}$ edition

6. Parveen Kumar, Michael Clark. Kumar \& Clark 'Clinical Medicine $8^{\text {th }}$ edition 13 664-666 